\title{
TEMPORAL CHARACTERIZATION OF AIRCRAFT NOISE SOURCES
}

\author{
Ferdinand W. Grosveld ${ }^{\otimes}$ \\ Lockheed Martin Engineering and Sciences \\ Hampton, VA 23681 \\ Brenda M. Sullivan ${ }^{\dagger}$ and Stephen A. Rizzi * \\ NASA Langley Research Center \\ Hampton, VA 23681
}

\begin{abstract}
Current aircraft source noise prediction tools yield time-independent frequency spectra as functions of directivity angle. Realistic evaluation and human assessment of aircraft fly-over noise require the temporal characteristics of the noise signature. The purpose of the current study is to analyze empirical data from broadband jet and tonal fan noise sources and to provide the temporal information required for prediction-based synthesis. Noise sources included a one-tenth-scale engine exhaust nozzle and a one-fifthscale scale turbofan engine. A methodology was developed to characterize the low frequency fluctuations employing the Short Time Fourier Transform in a MATLAB ${ }^{\circledR}$ computing environment. It was shown that a trade-off is necessary between frequency and time resolution in the acoustic spectrogram. The procedure requires careful evaluation and selection of the data analysis parameters, including the data sampling frequency, Fourier Transform window size, associated time period and frequency resolution, and time period window overlap. Low frequency fluctuations were applied to the synthesis of broadband noise with the resulting records sounding virtually indistinguishable from the measured data in initial subjective evaluations. Amplitude fluctuations of blade passage frequency (BPF) harmonics were successfully characterized for conditions equivalent to take-off and approach. Data demonstrated that the fifth harmonic of the BPF varied more in frequency than the BPF itself and exhibited larger amplitude fluctuations over the duration of the time record. Frequency fluctuations were found to be not perceptible in the current characterization of tonal components.
\end{abstract}

\footnotetext{
${ }^{\otimes}$ Aerospace Engineering Manager, Associate Fellow

${ }^{\dagger}$ Aerospace Research Engineer

*Aerospace Research Engineer, Associate Fellow
}

\section{INTRODUCTION}

In psychoacoustic studies at NASA Langley Research Center human subjects listen to aircraft flyover sounds and rate them according to various scoring methodologies. The subjective acoustic experiments take place in the field or under controlled laboratory conditions. Field tests using real aircraft flying over the subjects are challenging because it is not known precisely what each listener is hearing, the same flyover can never be reproduced exactly, and flight tests are expensive. Therefore, NASA Langley has historically presented flyover recordings or syntheses for evaluation using loudspeakers in laboratory listening situations. The outdoor environment is typically represented using an anechoic room or an acoustically treated auditorium with up to ten speakers in the walls and ceiling. ${ }^{1-4}$ Such laboratory situations allow more control of the test conditions than field-testing. Signals can be exactly replayed, the same sound can be played at different levels, and predicted aircraft sounds of the future can be synthesized. However, improvements in the spatial feel and time varying characteristics of the acoustic records are needed before the actual flyover sounds can be faithfully reproduced in the artificial laboratory setting. One method is the use of binaural recordings made with a dummy mannequin in a field test and played back to subjects over headphones, avoiding the impurities of the room acoustic playback characteristics. While such an approach gives a convincing presence, the playback is limited to the fixed orientation in which the recording was made. This prevents the subjects from localizing the sound source by both visual and aural means, turning their heads as they would do in the real world.

In an attempt to retain a controllable test environment, yet more closely recreate conditions in the field, a new capability was developed, ${ }^{5}$ which allows subjects to be immersed both visually and 
aurally in a three-dimensional, exterior virtual environment. Head tracking (real-time measurement of a listener's head orientation), real time graphics rendering and binaural simulation allow the presence to be maintained as the subject interacts with the test environment. Examples of the system's capabilities in the form of AVI (Audio Video Interleaved) movies are available at http://stabserv.larc.nasa.gov/flyover/. These examples used monaural flyover recordings and virtually positioned the sound in threedimensional space based on the emission position of the aircraft. The eventual use of the simulation is to perform subjective testing of low-noise flight operations. Using recorded aircraft flyover noise for this purpose is limited in value by the existence of extraneous noise in the recordings (natural or artificial), the finite number of fixed recording positions and the cost of conducting the flight tests. Perhaps the most limiting factor is the inability to examine proposed aircraft, engines, flight procedures, and other conditions or configurations for which, obviously, recorded data are not available. Synthesis of aircraft flyover noise as an alternative to recordings is therefore desirable.

\section{AIRCRAFT FLYOVER NOISE SYNTHESIS}

An earlier aircraft noise synthesizer, ${ }^{6}$ developed for simplified flight paths and component noise sources, was not suitable for synthesizing the sounds required in future studies of low noise flight operations. Instead, a new two-stage approach was developed for synthesizing flyover noise for arbitrarily complex sources and flight paths. ${ }^{7,8}$ The first stage entails synthesizing source time histories (at the flying source) based on the listener-aircraft spatial relationship. Rizzi and Sullivan ${ }^{7}$ developed an approach for synthesizing sound from broadband sources (e.g. jet noise) by filtering pink noise in the time domain through filters obtained from timeaveraged one-third octave band source directivities. An effort is underway to synthesize source time histories of tone-dominated sources (e.g. fan noise). The second stage entails propagation of the synthesized sound from the flying source to the listener at a specified location on the ground. ${ }^{8}$ Included are the effects of dynamic absolute delay of sound and location (producing accurate Doppler frequency shift and emission position), spreading loss, atmospheric attenuation, and binaural filtering. Whereas the first stage prediction analysis and synthesis are computed a priori, the second stage is performed in real-time, allowing creation of an immersive test environment.
For the first stage broadband noise synthesis, source frequency spectra as a function of directivity angle were obtained from ANOPP (Aircraft Noise Prediction Program). ${ }^{9} \quad$ Sound pressure level predictions from a jet engine as a function of frequency and directivity angle are shown in Figure 1. Data from such analyses are typically time-averaged. Thus, the temporal fluctuations that exist due to unsteadiness of the actual sources are not represented. Figure 2 shows the time history of measured jet noise data obtained in the NASA Langley Research Center Low Speed Aeroacoustic Wind Tunnel. The corresponding time-averaged one-third octave band spectrum is shown in Figure 3. Filters obtained from this spectrum served as input to the broadband noise synthesis. The time history of the synthesized sound is also shown in Figure 2 and its time-averaged spectrum in Figure 3. It is apparent that the timeaveraged spectra agree well, but that the time histories differ. The measured data contains lowfrequency fluctuations below the range of human hearing $(\sim 20 \mathrm{~Hz})$ that continuously modulate its spectrum. The synthesized data is based on the timeaveraged spectra and do not contain this modulation. The modulation effects must be added to the synthesis to create a time history that sounds realistic. The purpose of the current study is to analyze measured jet and tonal fan noise data and to characterize their low-frequency temporal fluctuations for use in prediction-based synthesis. Time dependent changes to the one-third octave band spectral amplitudes are required to characterize the broadband jet noise. Time dependent changes to the amplitude and the frequency of the blade passage frequency and harmonics are sought for the characterization of the fan noise source.

\section{JET AND FAN NOISE DATA SETS}

\section{Jet Broadband Noise}

A 3.33 seconds long data record was used to characterize the broadband noise from a scaled jet. It consisted of noise measurements made along a line parallel to the axis of an engine exhaust nozzle model in the Low Speed Aeroacoustic Wind Tunnel (LSAWT) at the NASA Langley Jet Noise Laboratory (Figure 4). The microphone time data were acquired at 150000 samples/second with no ensemble averaging. The forward flight Mach number in the tunnel was 0.1 . The model system had a by-pass ratio (BPR) of 5 and a separate flow exhaust system with core chevrons and a pylon. Operating conditions of the core and fan streams of the jet engine are listed in Table 1, including the nozzle pressure ratio (NPR), 
the total and static temperatures, the velocity, Mach number and density. There was no forced mixer on the jet other than the chevrons on the core jet. The model scale was $1 / 10$. The sampling rate was converted down to 15000 samples/second for a fullscale recording of 33.33 seconds. The microphones were located outside the free jet shear layer. The 28 microphone positions were along a line parallel to the longitudinal axis of the engine, at a perpendicular distance of $3.518 \mathrm{~m}$ from the engine axis, and at varying distances from the nozzle (outlet) with microphone 1 at $-1.932 \mathrm{~m}$ forward and microphone 28 at $7.679 \mathrm{~m}$ aft of the jet exhaust (forward being negative and aft being positive). The $\mathrm{X}$ and $\mathrm{Y}$ coordinates of the 28 measurement locations relative to the center of the jet exhaust plane, and their angle with the vertical Y-axis, are listed in Table 2.

\section{$\underline{\text { Fan Tonal Noise }}$}

The second data set was used to characterize the tonal noise from a 22-bladed scale model fan. The diameter of the fan was $0.559 \mathrm{~m}$. Measurements were performed in the Low Speed Wind Tunnel (LSWT) at NASA Glenn Research Center. The test section of the wind tunnel is $2.74 \mathrm{~m} \mathrm{(9} \mathrm{ft)} \mathrm{high} \mathrm{and} 4.57 \mathrm{~m}$ (15 $\mathrm{ft}$ ) wide, and provides airspeeds from 0 to $78.2 \mathrm{~m} / \mathrm{s}$. Data were obtained at a tunnel Mach number of 0.1 for fan rotational speeds of 12810 revolutions per minute (RPM) for the take-off condition and 7905 RPM for the approach. The take-off condition occurred at $100 \%$ of the design speed, while the approach condition took place at $61.7 \%$ design speed. Measurements were conducted at 12 positions of a traversing microphone. The microphone traveled along a path parallel to, and at a distance of $2.235 \mathrm{~m}$ from, the fan axis. The angular measurement positions in front (negative values) and aft of the fan rotational plane are indicated in Table 3 for both the approach and take-off fan operating conditions. The data records were converted to $1 / 5$ of the original sampling rate (from 105263 to 21052.6 samples/second) to reflect full-size conditions. The lengths of the data records were increased by that conversion from 14.61 seconds to 73.06 seconds. Frequency and amplitude variations of the fundamental and harmonics will be characterized as function of time.

\section{ANALYSIS}

\section{Short Time Fourier Transform (STFT)}

In the STFT analysis a moveable window is applied to the signal to create a number of successive short time periods. A Discrete Time Fourier Transform is employed to convert the time signal in each of these periods to a frequency spectrum. The resulting spectrogram is the time-frequency representation of the signal. Variations in the time signal within each period cannot be resolved. The analysis across multiple periods produces the time variation of the signal. Discretisation of the time signal in the time and amplitude domain is performed at the sampling rate $f_{s}$. The sampling rate $f_{s}$ is related to the inverse of the time period $\mathrm{T}$ by the number of points $\mathrm{N}$ in the Fourier Transform:

$$
\mathrm{f}_{\mathrm{s}}=\mathrm{N} / \mathrm{T}
$$

The time period is inversely proportional to the bandwidth of each frequency bin $(\Delta \mathrm{f})$ :

$$
\mathrm{T}=1 / \Delta \mathrm{f}
$$

A shorter time period corresponds to a wider frequency bandwidth and hence a poorer frequency resolution. The STFT provides constant resolution in both time and frequency. The time and frequency resolutions remain fixed after the Fourier Transform window size $(\mathrm{N})$ has been chosen. For optimal results a trade-off between the time resolution and the frequency resolution is required. The Nyquist theorem defines the maximum frequency that can be restored from a digital signal as half the sampling frequency.

\section{Broadband Analysis}

The $150000 \mathrm{~Hz}$ sampling rate of the model time signal was converted down to a $15000 \mathrm{~Hz}$ sampling rate to scale the frequency content of the signal to the sound of the full-scale engine, thereby increasing the total length of the time signal to 33.33 seconds. The corresponding Nyquist (maximum) analysis frequency was $7500 \mathrm{~Hz}$. The amplitude of the signal was not altered. The time periods and the frequency resolutions are listed in Table 4 for selected Fourier Transform window sizes. Broadband analyses were performed in one-third octave bands. A requirement was formulated to have at least the equivalent of two full narrowband frequency bins available in each onethird octave band for the analysis. Table 5 shows the number of full frequency bins fitting in each one-third octave band up to $160 \mathrm{~Hz}$. Also indicated in Table 5 are the one-third octave band center frequencies, their related passbands and their frequency bandwidths. Table 5 shows that a Fourier Transform window size $(\mathrm{N})$ of at least $8192\left(2^{13}\right)$ points is required to resolve frequencies down to the $20 \mathrm{~Hz}$ one-third octave band. 
This corresponds to a time period of $\mathrm{T}=0.5461$ seconds (Table 4). Selected frequencies (f) from 0.25 $\mathrm{Hz}$ to $20 \mathrm{~Hz}$ and associated time intervals $(\Delta \mathrm{t}=1 / \mathrm{f})$ are listed in Table 6. A requirement of two data points for each time interval $\Delta \mathrm{t}$ was used to resolve the lowfrequency fluctuations per the Nyquist criterion. Table 6 also shows the number of data points (time periods $\mathrm{T}$ ) that fit within the required time interval $\Delta t$ as a function of the Fourier Transform window size. It is observed that for a Fourier Transform window size of 8192 the requirement is met only up to $0.5 \mathrm{~Hz}$. By overlapping successive time periods $\mathrm{T}$ more data points are created. The overlap is expressed as a percentage of the time period $\mathrm{T}$. The non-overlap time between data points is designated the time segment $\delta \mathrm{t}$. Table 4 lists the time segments $\delta \mathrm{t}_{95.5}$ for a 95.5\% overlap. However, although more data points are available for the analysis, the original time period of the moveable window is still the same. The number of time segments $\delta t_{95.5}$ within each time interval $\Delta \mathrm{t}$ for the $95.5 \%$ overlap is listed in Table 7 . For window sizes less than 8192 points, all frequencies equal to or below $20 \mathrm{~Hz}$ are now included as they meet the Nyquist criterion.

The MATLAB ${ }^{\circledR}$ software package was used for the time-frequency analysis and post-processing of all 28 microphone signals. Only some of the results for microphone number 28 are discussed in this publication. Microphone 28 is located 65.4 degrees behind the jet exhaust plane as indicated in Table 2 . The low-frequency temporal characteristics $(<20 \mathrm{~Hz})$ were determined for each of the $20 \mathrm{~Hz}$ to $5000 \mathrm{~Hz}$ one-third octave bands. The narrowband spectrogram results were converted to one-third octave bands by adding the pressure-squared components, or parts thereof, in each one-third octave frequency band and each time segment. The resulting spectrogram is depicted in Figure 5 for $95.5 \%$ overlap. The sound pressure level is shown in $\mathrm{dB}$ (re $20 \mu \mathrm{Pa}$ ) as function of the one-third octave band center frequencies from $20 \mathrm{~Hz}$ through $5000 \mathrm{~Hz}$ and as function of the time from 0 through 33.33 seconds. The noise is dominated by the $20 \mathrm{~Hz}-125 \mathrm{~Hz}$ low frequency onethird octave bands, as was expected in the aft arc region of the jet. The fluctuations of the sound pressure levels about the time average in each onethird octave band are presented in Figure 6 for $95.5 \%$ overlap.

The same analysis and post-processing method was used in calculating the fluctuations about the time average of the synthesized sound pressure levels, obtained without adding the effect of low-frequency time variations. The synthesis used as its basis the time average of the measured one-third octave band spectra, shown in Figure 3. The temporal variation analysis was also performed with $95.5 \%$ overlap. Fluctuations are present due to the pink noise used in the synthesis of the jet noise signal. The spectrogram in Figure 7 shows that the low frequency fluctuations without adding the low frequency time variations of the synthesized signal are substantially less than the low frequency fluctuations of the wind tunnel model data set (Figure 6). Although the average one-third octave band spectrum of the synthesized record agrees well with that of the measured data (Figure 3), it lacks the temporal character of the actual jet noise records.

The synthesis was repeated, using as its basis the same time average of the measured one-third octave spectra, but using the low frequency time variations shown in Figure 6 to modulate the signal as described in Reference 8. A temporal variation analysis of the results was performed using $95.5 \%$ overlap. It is shown in Figure 8 that the temporal variations closely match those of the original wind tunnel data, which were presented in Figure 6. The synthesized record, with the temporal variations incorporated, sounded virtually indistinguishable from the measured data, demonstrating the efficacy of the present time variation analysis and its use in the synthesis. The sound files of the recorded jet noise, the synthesized jet noise without, and the synthesized jet with the temporal variations are available in the form of '.wav' files at http://stabserv.larc.nasa.gov/flyover/

\section{$\underline{\text { Tonal Analysis }}$}

Acoustic wind tunnel data from a model fan were obtained, as described previously, for conditions equivalent to approach and take-off. Both data records were converted down to 21052.6 samples/second corresponding to a full size turbofan. The length of the data records increased from 14.61 seconds to 73.06 seconds. The time periods and the frequency resolutions are listed in Table 8 for selected Fourier Transform window sizes. The frequency bandwidth needs to be chosen sufficiently small to contain primarily the intended blade passage frequency (BPF) harmonic and not adjacent tonal components or interfering broadband noise. A frequency resolution of less than $1 \mathrm{~Hz}$ was considered necessary. Table 8 indicates that if a frequency resolution of $0.6425 \mathrm{~Hz}$ is selected the Fourier Transform window size has to be at least 32768 , which corresponds to a time period of 1.5565 seconds. The number of data points (time periods $\mathrm{T}$ ) within the required time interval $\Delta \mathrm{t}$ of the low 
frequency fluctuations was calculated for each Fourier Transform window size and is presented in Table 9. At least two data points are required to resolve the low-frequency fluctuations. It is shown in Table 9 that the highest frequency resolution is only $0.25 \mathrm{~Hz}$ for the 32768 Fourier Transform window size. A $98.4 \%$ overlap $\left(\delta t_{98.4}=0.0249\right.$ in Table 8$)$ is required to obtain the necessary number of data points and resolve all low frequency fluctuations below $20 \mathrm{~Hz}$, as indicated in Table 10. However, the number of time segments that need to be processed increases by a factor of 62.5 , creating computational requirements that were larger than the resources available for the desktop based MATLAB ${ }^{\circledR}$ program. Since the ear is most sensitive to changes at a $4 \mathrm{~Hz}$ modulation frequency, ${ }^{10}$ it was decided to choose a time overlap of $92.0 \%$. This time overlap $\left(\delta \mathrm{t}_{92.0}=\right.$ 0.1245 in Table 8) provides the required two data points within the time resolution at the $4 \mathrm{~Hz}$ low frequency modulation (Table 11). The 73.06 seconds long take-off and approach time records were analyzed with the 32768 Fourier Transform window size and $92 \%$ overlap for the microphone located in the fan rotational plane (0-deg angle).

Take-Off Conditions - The 12810 revolutions per minute fan engine speed of the wind tunnel model for conditions equivalent to take off was calculated to produce a fundamental BPF of $939.4 \mathrm{~Hz}$ for a fullscale fan engine. Figure 8 shows the narrow band frequency spectrum measured in the fan rotational plane of the scale model but converted in frequency to the equivalent full-scale jet engine. The BPF is indicated by the encircled number (1) in Figure 9. Also shown are harmonics of the BPF at $1878.8 \mathrm{~Hz}$ $\left(2^{\text {nd }}\right), 2818.2 \mathrm{~Hz}\left(3^{\text {rd }}\right), 3757.6 \mathrm{~Hz}\left(4^{\text {th }}\right)$, and $4697.0 \mathrm{~Hz}$ $\left(5^{\text {th }}\right)$. Several multiples of the $42.7 \mathrm{~Hz}$ rotational speed of the fan shaft are also visible in the frequency spectrum of Figure 9. The Nyquist (maximum) analysis frequency was $10526.3 \mathrm{~Hz}$. The amplitude of the signal was not altered. The spectrogram of the time record was computed for ten frequency bins encompassing the fundamental BPF at $939.4 \mathrm{~Hz}$, as shown in Figure 10. Each frequency bin was 0.6425 $\mathrm{Hz}$ wide as was determined by the choice of the 32768 wide Fourier Transform window size (Table 8). The pressure amplitude is expressed in Pascals. The maximum pressure does not occur in the same frequency bin as time progresses, but changes across several frequency bins. The analysis employed a Hanning window for the Fourier Transform, which adds side lobes to the frequency component and broadens its base. Also, the frequency spectrum is averaged over each time period. If the frequency varies within that time period than the averaged frequency component will be broader in nature. The pressures in the frequency bins on either side are added to the maximum pressure to make sure nearly all the energy of the broader frequency component is captured. Including more frequency bins would only add broadband noise, which does not characterize the tonal component. After identifying the maximum pressure in each time segment the time average of all the maximum pressures was computed over the entire 73.06-second time record. The fluctuations of the sound pressure level (re $20 \mu \mathrm{Pa}$ ) about the average maximum level are displayed as a function of time in Figure 11. Figure 12 shows the spectrogram of the time record for 10 frequency bins encompassing the fifth BPF harmonic $(4697.0 \mathrm{~Hz})$. The width of the frequency bins $(0.6425 \mathrm{~Hz})$ is the same as for the fundamental BPF shown in Figure 10. However, the frequency bins in which the maximum pressure occurs within each time period are more spread out over several bins as time progresses. The pressures in the two adjacent bins were again added to the maximum pressure for each time segment and the average over all segments of the time record was calculated. Figure 13 shows the sound pressure level variation about the average of the maximum sound pressure levels. Figures 12 and 13 indicate that the fifth harmonic of the BPF varies more in frequency and exhibits larger amplitude fluctuations over the duration of the time record compared with the fundamental blade passage frequency.

Approach Conditions - The 7905 revolutions per minute rotational speed for the approach conditions of the scale model produced a fundamental BPF of $579.7 \mathrm{~Hz}$ for a full-scale fan engine. The same analysis was performed on the acoustic time record as was done previously for the take-off condition. The frequency spectrum of the acoustic data record for the microphone location in the fan rotational plane does not show the fundamental BPF (Figure 14). Harmonics of the BPF do show in the spectrum of Figure 14 at $1159.4 \mathrm{~Hz}\left(2^{\text {nd }}\right), 1739.1 \mathrm{~Hz}\left(3^{\text {rd }}\right), 2318.8$ $\mathrm{Hz}\left(4^{\text {th }}\right), 2898.5 \mathrm{~Hz}\left(5^{\text {th }}\right), 3478.2 \mathrm{~Hz}\left(6^{\text {th }}\right)$, and 4057.9 $\mathrm{Hz}\left(7^{\text {th }}\right)$. The spectrogram of the second BPF harmonic is shown in Figure 15. The pressures in the frequency bins on either side were added to the maximum pressure to ensure that virtually all energy of the broader frequency component was captured. After calculating the maximum pressures in each time segment, the time average maximum pressure was computed over the entire 73.06-second time record. The fluctuations in the sound pressure level (re $20 \mu \mathrm{Pa}$ ) about the average sound pressure level as a function of time is displayed in Figure 16. Figure 17 shows the spectrogram of the time record for 10 
frequency bins encompassing the fifth BPF harmonic $(2898.5 \mathrm{~Hz})$. The frequency bin in which the maximum pressure occurs within each time segment is more spread out over several frequency bins, similar to the fifth BPF harmonic for the take-off condition in Figure 12. The pressures in the two adjacent bins were again added to the maximum pressure for each time period and the average over all segments of the time record was calculated. Figure 18 shows the sound pressure level variation about the average of maximum sound pressure levels. It is shown that the fifth harmonic of the BPF varies more in frequency and exhibits larger amplitude fluctuations over the duration of the time record, compared with the lower blade passage frequencies.

Frequency fluctuations - In addition to the time dependent amplitude fluctuations, the variations of the time dependent tonal frequencies need to be addressed. Zwicker ${ }^{10}$ gives a relationship for the "just noticeable variation in frequency" (jnvf) of a pure tone of frequency $\mathrm{f}$ as about $0.007 * \mathrm{f}$ for $\mathrm{f}>500 \mathrm{~Hz}$, and $3.6 \mathrm{~Hz}$ for $\mathrm{f}<500 \mathrm{~Hz}$. At the $939.4 \mathrm{~Hz}$ take-off BPF the jnvf equals $6.58 \mathrm{~Hz}$. The BPF maximum pressures in Figure 10 occur within four frequency bins with a $2.57 \mathrm{~Hz}$ total bandwidth, which is lower than the jnvf at that frequency. A jnvf of 32.88 was calculated for the fifth BPF harmonic at $4697.0 \mathrm{~Hz}$. It is shown in Figure 12 that the maximum pressures occur within a $4.50 \mathrm{~Hz}$ bandwidth (seven frequency bins), well below the jnvf calculated at that frequency. The frequency fluctuations in the spectrograms of Figures 15 and 17 also varied less than their respective calculated just-noticeable changes. Comparison of the frequency fluctuations from the other microphone data with the jnvf criteria, which are not presented here, suggests that these variations are not perceptible for any of the tonal frequencies in the current characterization. Therefore, amplitude modulation, but not frequency modulation, needs to be incorporated into the tonal synthesis.

\section{CONCLUDING REMARKS}

A methodology was developed to characterize the low frequency fluctuations in broadband jet noise and tonal fan noise employing the Short Time Fourier Transform in a MATLAB ${ }^{\circledR}$ computing environment. Noise sources included a one-tenth-scale engine exhaust nozzle model and a one-fifth-scale turbofan engine. It was shown that a trade-off is necessary between frequency and time resolution in the acoustic spectrogram. The procedure requires careful evaluation and selection of the data analysis parameters, including the data sampling frequency, Fourier Transform window size, associated time period and frequency resolution, and time window overlap. Low frequency fluctuations were applied to the synthesis of broadband noise predictions with the resulting records sounding indistinguishable from the recorded data in preliminary subjective evaluations. Amplitude fluctuations of BPF harmonics were successfully characterized for conditions equivalent to take-off and approach. Data demonstrated that the fifth harmonic of the BPF varied more in frequency and exhibited larger amplitude fluctuations over the duration of the time record compared with the lower blade passage frequencies. Frequency fluctuations were found to be not perceptible in the current characterization of tonal components.

\section{ACKNOWLEDGEMENT}

This work was supported by NASA Langley Research Center, NAS1-00135, Dr. Richard J. Silcox, Technical Monitor.

\section{REFERENCES}

1. McCurdy, D.A. and Powell, C.A., "Annoyance caused by propeller airplane flyover noise," NASA TP 2356, August 1984.

2. McCurdy, D.A., "Annoyance caused by advanced turboprop aircraft flyover noise, single-rotating-propeller configuration," NASA TP 2782, March 1988.

3. McCurdy, D.A., “Annoyance caused by advanced turboprop aircraft flyover noise, counter-rotating-propeller configuration," NASA TP 3027, September 1990.

4. Leatherwood, J.D. and Sullivan, B.M., "A laboratory study of subjective annoyance response to sonic booms and aircraft flyovers," NASA TM 109113, May 1994.

5. Rizzi, S.A., Sullivan, B.M., and Sandridge, C.A., "A threedimensional virtual simulator for aircraft flyover presentation," Proceedings of the 2003 International Conference on Auditory Display, Boston, MA, 2003.

6. McCurdy, D.A. and Grandle, R.E., "Aircraft noise synthesis system,” NASA TM-89040, February 1987.

7. Rizzi, S.A. and Sullivan, B.M., "Prediction-based aircraft flyover noise synthesis," $145^{\text {th }}$ Meeting of the Acoustical Society of America, Nashville, TN, April 28 - May 2, 2003. Abstract in Journal of the Acoustical Society of America, Vol. 113 , p. $2245,2003$.

8. Rizzi, S.A., Sullivan, B.M., and Cook, B.A., "Signal processing for aircraft noise synthesis and propagation," $146^{\text {th }}$ Meeting of the Acoustical Society of America, Austin, TX, November 10-14, 2003. Abstract in Journal of the Acoustical Society of America, Vol. 114, (4) p. 2340, 2003.

9. Gillian, R.E., “Aircraft noise prediction program user's manual,” NASA TM-84486, January 1983.

10. Zwicker, E. and Fastl, H, "Psychoacoustics: facts and models," Springer-Verlag, Berlin, 1990. 
AIAA 2004-1029

\section{TABLES}

Table 1. Operating conditions of the core and fan streams of the model jet for broadband noise data acquisition.

\begin{tabular}{lccccccc}
\hline & Area & $\begin{array}{c}\text { Nozzle Pressure } \\
\text { Ratio (NPR) } \\
{[-]}\end{array}$ & $\begin{array}{c}\text { Total } \\
\text { Temperature } \\
{\left[{ }^{\circ} \mathrm{K}\right]}\end{array}$ & $\begin{array}{c}\text { Static } \\
\text { Temperature } \\
{\left[{ }^{\circ} \mathrm{K}\right]}\end{array}$ & $\begin{array}{c}\text { Velocity } \\
{[\mathrm{m} / \mathrm{s}]}\end{array}$ & $\begin{array}{c}\text { Mach } \\
\text { Number } \\
{[-]}\end{array}$ & $\begin{array}{c}\text { Density } \\
{\left[\mathrm{kg} / \mathrm{m}^{3}\right]}\end{array}$ \\
\hline Core Stream & 0.00691 & 1.56 & 828.3 & 729.4 & 446.8 & 0.823 & 0.48446 \\
Fan Stream & 0.01839 & 1.75 & 359.4 & 306.1 & 326.8 & 0.931 & 1.15445 \\
\hline
\end{tabular}

Table 2. The $\mathrm{X}$ and $\mathrm{Y}$ coordinates and the angle with the vertical $\mathrm{Y}$-axis of the broadband noise measurement locations relative to the center of the jet exhaust plane (forward positions have a negative $\mathrm{X}$ coordinate).

\begin{tabular}{|c|c|c|c|c|c|c|c|c|c|c|c|}
\hline \multirow{2}{*}{$\begin{array}{c}\text { Microphone } \\
\text { Number } \\
{[-]}\end{array}$} & \multicolumn{2}{|c|}{ Coordinate } & \multirow[b]{2}{*}{$\begin{array}{c}\text { Angle } \\
\text { [deg] }\end{array}$} & \multirow{2}{*}{$\begin{array}{c}\text { Microphone } \\
\text { Number } \\
{[-]}\end{array}$} & \multicolumn{2}{|c|}{ Coordinate } & \multirow[b]{2}{*}{$\begin{array}{c}\text { Angle } \\
{[\mathrm{deg}]}\end{array}$} & \multirow{2}{*}{$\begin{array}{c}\text { Microphone } \\
\text { Number } \\
{[-]}\end{array}$} & \multicolumn{2}{|c|}{ Coordinate } & \multirow[b]{2}{*}{$\begin{array}{l}\text { Angle } \\
\text { [deg] }\end{array}$} \\
\hline & $\begin{array}{l}X \\
{[\mathrm{~m}]}\end{array}$ & $\begin{array}{c}\mathrm{Y} \\
{[\mathrm{m}]}\end{array}$ & & & $\begin{array}{c}\mathrm{X} \\
{[\mathrm{m}]}\end{array}$ & $\begin{array}{c}\mathrm{Y} \\
{[\mathrm{m}]}\end{array}$ & & & $\begin{array}{c}\mathrm{X} \\
{[\mathrm{m}]}\end{array}$ & $\begin{array}{c}\mathrm{Y} \\
{[\mathrm{m}]}\end{array}$ & \\
\hline 1 & -1.932 & 3.518 & -28.77 & 11 & 1.894 & 3.518 & 28.30 & 20 & 4.538 & 3.518 & 52.22 \\
\hline 2 & -1.366 & 3.518 & -21.22 & 12 & 2.206 & 3.518 & 32.09 & 21 & 4.809 & 3.518 & 53.82 \\
\hline 3 & -0.877 & 3.518 & -14.00 & 13 & 2.529 & 3.518 & 35.71 & 22 & 5.104 & 3.518 & 55.42 \\
\hline 4 & -0.445 & 3.518 & -7.21 & 14 & 2.866 & 3.518 & 39.17 & 23 & 5.425 & 3.518 & 57.04 \\
\hline 7 & 0.643 & 3.518 & 10.36 & 17 & 3.827 & 3.518 & 47.41 & 26 & 6.610 & 3.518 & 61.98 \\
\hline 8 & 0.966 & 3.518 & 15.35 & 18 & 4.049 & 3.518 & 49.02 & 27 & 7.108 & 3.518 & 63.67 \\
\hline 9 & 1.278 & 3.518 & 19.97 & 19 & 4.285 & 3.518 & 50.62 & 28 & 7.679 & 3.518 & 65.39 \\
\hline 10 & 1.586 & 3.518 & 24.27 & & & & & & & & \\
\hline
\end{tabular}

Table 3. Model fan operating conditions and traverse microphone tonal noise measurement conditions.

\begin{tabular}{|c|c|c|c|c|c|c|c|c|c|c|c|c|c|c|}
\hline \multirow{2}{*}{$\begin{array}{c}\text { Condition } \\
\text { Take-off }\end{array}$} & \multirow{2}{*}{$\begin{array}{c}\begin{array}{c}\mathrm{RPM} \\
{[\mathrm{rev} / \mathrm{min}]}\end{array} \\
12810\end{array}$} & \multirow{2}{*}{$\begin{array}{c}\begin{array}{c}\text { Design Speed } \\
{[\%]}\end{array} \\
100.0\end{array}$} & \multicolumn{12}{|c|}{$\begin{array}{l}\text { Microphone Location (Angle with the fan rotational plane; negative is forward) } \\
\text { [deg] }\end{array}$} \\
\hline & & & -65 & -59 & -49 & -40 & -29 & -20 & -9 & 0 & 12 & 21 & 31 & 40 \\
\hline Approach & 7905 & 61.7 & -65 & -59 & -49 & -40 & -29 & -20 & -9 & 0 & 12 & 21 & 31 & 40 \\
\hline
\end{tabular}

Table 4. Broadband jet noise time lengths for no and $95.5 \%$ overlap, and frequency resolution for selected Fourier Transform window sizes.

\begin{tabular}{cccc}
\hline $\begin{array}{c}\text { Fourier Transform } \\
\begin{array}{c}\text { Window Size }(\mathrm{N}) \\
{[-]}\end{array}\end{array}$ & $\begin{array}{c}\text { Time Period }(\mathrm{T}) \\
(\text { No Overlap) } \\
{[\mathrm{s}]}\end{array}$ & $\begin{array}{c}\text { Frequency } \\
\operatorname{Bin}(\Delta \mathrm{f}=1 / \mathrm{T}) \\
{[\mathrm{Hz}]}\end{array}$ & $\begin{array}{c}\text { Time Segment }\left(\delta \mathrm{t}_{95.5}\right) \\
(95.5 \% \text { Overlap }) \\
{[\mathrm{s}]}\end{array}$ \\
\hline 2048 & 0.1365 & 7.3242 & 0.0061 \\
4096 & 0.2731 & 3.6621 & 0.0123 \\
8192 & 0.5461 & 1.8311 & 0.0246 \\
16384 & 1.0923 & 0.9155 & 0.0492 \\
\hline
\end{tabular}

Table 5. Number of frequency bins $(\Delta \mathrm{f})$ in each one-third octave bandwidth (bw) of broadband jet noise as a function of Fourier Transform Window Size (N) for zero overlap

\begin{tabular}{|c|c|c|c|c|c|c|c|}
\hline \multirow{2}{*}{$\begin{array}{c}\text { One-third } \\
\text { Octave Band } \\
{[\mathrm{Hz}]}\end{array}$} & \multirow{2}{*}{$\begin{array}{c}\text { Center } \\
\text { Frequency } \\
{[\mathrm{Hz}]}\end{array}$} & \multirow{2}{*}{$\begin{array}{c}\text { One-third Octave } \\
\text { Pass Band } \\
{[\mathrm{Hz}]}\end{array}$} & \multirow{2}{*}{$\begin{array}{c}\text { One-third Octave } \\
\text { Bandwidth (bw) } \\
{[\mathrm{Hz}]}\end{array}$} & \multicolumn{4}{|c|}{ bw/ $\Delta \mathrm{f}$} \\
\hline & & & & 2048 & 4096 & 8192 & 16384 \\
\hline 20 & 19.95 & $17.8-22.4$ & 4.6 & 0 & 1 & 2 & 5 \\
\hline 25 & 25.12 & $22.4-28.2$ & 5.8 & 0 & 1 & 3 & 6 \\
\hline 31.5 & 31.62 & $28.2-35.5$ & 7.3 & 0 & 1 & 3 & 7 \\
\hline 40 & 39.81 & $35.5-44.7$ & 9.2 & 1 & 2 & 5 & 10 \\
\hline 50 & 50.12 & $44.7-56.2$ & 11.5 & 1 & 3 & 6 & 12 \\
\hline 63 & 63.10 & $56.2-70.8$ & 14.6 & 1 & 3 & 7 & 15 \\
\hline 80 & 79.43 & $70.8-89.1$ & 17.3 & 2 & 4 & 9 & 18 \\
\hline 100 & 100.00 & $89.1-112$ & 22.9 & 3 & 6 & 12 & 25 \\
\hline 125 & 125.89 & $112-141$ & 29 & 3 & 7 & 15 & 31 \\
\hline 160 & 158.49 & $141-178$ & 37 & 5 & 10 & 20 & 40 \\
\hline
\end{tabular}


Table 6. Number of broadband jet noise time periods (T) within the low frequency fluctuation time interval $(\Delta t)$ as a function of the Fourier Transform Window Size (N) for no overlap.

\begin{tabular}{cccccc}
\hline \multirow{2}{*}{$\begin{array}{c}\text { Frequency } \\
(\mathrm{f})\end{array}$} & $\begin{array}{c}\text { Time } \\
\text { Interval } \\
(\Delta \mathrm{t}=1 / \mathrm{f})\end{array}$ & \multicolumn{5}{c}{$\Delta \mathrm{t} / \mathrm{T}$} \\
{$[\mathrm{Hz}]$} & {$[\mathrm{s}]$} & 2048 & 4096 & 8192 & 16384 \\
\hline 0.25 & 4 & 29 & 14 & 7 & 3 \\
0.5 & 2 & 14 & 7 & 3 & 1 \\
1 & 1 & 7 & 3 & 1 & 0 \\
2 & 0.5 & 3 & 1 & 0 & 0 \\
3 & 0.333 & 2 & 1 & 0 & 0 \\
4 & 0.25 & 1 & 0 & 0 & 0 \\
5 & 0.2 & 1 & 0 & 0 & 0 \\
10 & 0.1 & 0 & 0 & 0 & 0 \\
15 & 0.067 & 0 & 0 & 0 & 0 \\
20 & 0.05 & 0 & 0 & 0 & 0 \\
\hline
\end{tabular}

Table 7. Number of broadband jet noise time segments $\left(\delta t_{95.5}\right)$ within the low frequency fluctuation time resolution $(\Delta t)$ as a function of Fourier Transform Window Size $(N)$ for $95.5 \%$ overlap.

\begin{tabular}{|c|c|c|c|c|c|}
\hline \multirow{3}{*}{$\begin{array}{c}\text { Frequency } \\
\text { (f) } \\
{[\mathrm{Hz}]}\end{array}$} & \multirow{3}{*}{$\begin{array}{c}\text { Time } \\
\text { Interval } \\
(\Delta \mathrm{t}=1 / \mathrm{f}) \\
{[\mathrm{s}]}\end{array}$} & \multicolumn{4}{|c|}{$\Delta \mathrm{t} / \delta \mathrm{t}_{95.5}$} \\
\hline & & Fourier & Transform & Window & $\operatorname{size}(\mathrm{N})$ \\
\hline & & 2048 & 4096 & 8192 & 16384 \\
\hline 0.25 & 4 & 651 & 325 & 162 & 81 \\
\hline 0.5 & 2 & 325 & 162 & 81 & 40 \\
\hline 1 & 1 & 162 & 81 & 40 & 20 \\
\hline 2 & 0.5 & 81 & 40 & 20 & 10 \\
\hline 3 & 0.333 & 54 & 27 & 13 & 6 \\
\hline 4 & 0.25 & 40 & 20 & 10 & 5 \\
\hline 5 & 0.2 & 32 & 16 & 8 & 4 \\
\hline 10 & 0.1 & 16 & 8 & 4 & 2 \\
\hline 15 & 0.067 & 10 & 5 & 2 & 1 \\
\hline 20 & 0.05 & 8 & 4 & 2 & 1 \\
\hline
\end{tabular}

Table 8. Time lengths for $0 \%, 98.4 \%$ and $92.0 \%$ overlap, and frequency resolutions for selected Fourier Transform window sizes in tonal fan noise analysis.

\begin{tabular}{|c|c|c|c|c|}
\hline Fourier & Time & & Time & Time \\
\hline Transform & Period & Frequency & Segment & Segment \\
\hline Window & & Resolution & (98.4\% & $(92.0 \%$ \\
\hline Size & Overlap) & & Overlap) & Overlap) \\
\hline$(\mathrm{N})$ & $(\mathrm{T})$ & $(\Delta \mathrm{f})$ & $\left(\delta t_{98.4}\right)$ & $\left(\delta t_{92.0}\right)$ \\
\hline$[-]$ & {$[\mathrm{s}]$} & {$[\mathrm{Hz}]$} & {$[\mathrm{s}]$} & {$[\mathrm{s}]$} \\
\hline 2048 & 0.0973 & 10.2796 & 0.0016 & 0.0078 \\
\hline 4096 & 0.1946 & 5.1398 & 0.0031 & 0.0156 \\
\hline 8192 & 0.3891 & 2.5699 & 0.0062 & 0.0311 \\
\hline 16384 & 0.7782 & 1.2850 & 0.0125 & 0.0623 \\
\hline 32768 & 1.5565 & 0.6425 & 0.0249 & 0.1245 \\
\hline 65536 & 3.1130 & 0.3212 & 0.0498 & 0.2490 \\
\hline
\end{tabular}

Table 9. Number of time periods (T) within the low frequency fluctuation time resolution $(\Delta t)$ as a function of the Fourier Transform Window Size $(\mathrm{N})$ for no overlap in tonal fan noise analysis.

\begin{tabular}{|c|c|c|c|c|c|}
\hline \multirow{2}{*}{$\begin{array}{c}\text { Frequency } \\
\text { (f) } \\
{[\mathrm{Hz}]}\end{array}$} & \multirow{2}{*}{$\begin{array}{c}\text { Time } \\
\text { Interval } \\
(\Delta \mathrm{t}=1 / \mathrm{f}) \\
{[\mathrm{s}]}\end{array}$} & \multicolumn{4}{|c|}{$\Delta \mathrm{t} / \mathrm{T}$} \\
\hline & & 8192 & 16384 & 32768 & 65536 \\
\hline 0.25 & 4 & 10 & 5 & 2 & 1 \\
\hline 0.5 & 2 & 5 & 2 & 1 & 0 \\
\hline 1 & 1 & 2 & 1 & 0 & 0 \\
\hline 2 & 0.5 & 1 & 0 & 0 & 0 \\
\hline 3 & 0.333 & 0 & 0 & 0 & 0 \\
\hline 4 & 0.25 & 0 & 0 & 0 & 0 \\
\hline 5 & 0.2 & 0 & 0 & 0 & 0 \\
\hline 10 & 0.1 & 0 & 0 & 0 & 0 \\
\hline 15 & 0.067 & 0 & 0 & 0 & 0 \\
\hline 20 & 0.05 & 0 & 0 & 0 & 0 \\
\hline
\end{tabular}

Table 10. Number of time segments $\left(\delta \mathrm{t}_{98.4}\right)$ within the low frequency fluctuation time resolution $(\Delta t)$ as a function of Fourier Transform Window Size (N) for $98.4 \%$ overlap in tonal fan noise analysis.

\begin{tabular}{|c|c|c|c|c|c|}
\hline \multirow{2}{*}{$\begin{array}{c}\text { Frequency } \\
\text { (f) } \\
{[\mathrm{Hz}]}\end{array}$} & \multirow{2}{*}{$\begin{array}{c}\text { Time } \\
\text { Interval } \\
(\Delta \mathrm{t}=1 / \mathrm{f}) \\
{[\mathrm{s}]}\end{array}$} & \multicolumn{4}{|c|}{$\Delta \mathrm{t} / \delta \mathrm{t}_{98.4}$} \\
\hline & & 8192 & 16384 & 32768 & 65536 \\
\hline 0.25 & 4 & 642 & 321 & 160 & 80 \\
\hline 0.5 & 2 & 321 & 160 & 80 & 40 \\
\hline 1 & 1 & 160 & 80 & 40 & 20 \\
\hline 2 & 0.5 & 80 & 40 & 20 & 10 \\
\hline 3 & 0.333 & 53 & 26 & 13 & 6 \\
\hline 4 & 0.25 & 40 & 20 & 10 & 5 \\
\hline 5 & 0.2 & 32 & 16 & 8 & 4 \\
\hline 10 & 0.1 & 16 & 8 & 4 & 2 \\
\hline 15 & 0.067 & 10 & 5 & 2 & 1 \\
\hline 20 & 0.05 & 8 & 4 & 2 & 1 \\
\hline
\end{tabular}

Table 11. Number of time segments $\left(\delta \mathrm{t}_{92.0}\right)$ within the low frequency fluctuation time resolution $(\Delta t)$ as a function of Fourier Transform Window Size (N) for $92.0 \%$ overlap in tonal fan noise analysis.

\begin{tabular}{|c|c|c|c|c|c|}
\hline \multirow{3}{*}{$\begin{array}{c}\text { Frequency } \\
\text { (f) } \\
{[\mathrm{Hz}]}\end{array}$} & \multirow{3}{*}{$\begin{array}{c}\text { Time } \\
\text { Interval } \\
(\Delta \mathrm{t}=1 / \mathrm{f}) \\
{[\mathrm{s}]}\end{array}$} & \multicolumn{4}{|c|}{$\Delta \mathrm{t} / \delta \mathrm{t}_{92.0}$} \\
\hline & & Fourier & Transform & Window & Size $(N)$ \\
\hline & & 8192 & 16384 & 32768 & 65536 \\
\hline 0.25 & 4 & 128 & 64 & 32 & 16 \\
\hline 0.5 & 2 & 64 & 32 & 16 & 8 \\
\hline 1 & 1 & 32 & 16 & 8 & 4 \\
\hline 2 & 0.5 & 16 & 8 & 4 & 2 \\
\hline 3 & 0.333 & 10 & 5 & 2 & 1 \\
\hline 4 & 0.25 & 8 & 4 & 2 & 1 \\
\hline 5 & 0.2 & 6 & 3 & 1 & 0 \\
\hline 10 & 0.1 & 3 & 1 & 0 & 0 \\
\hline 15 & 0.067 & 2 & 1 & 0 & 0 \\
\hline 20 & 0.05 & 1 & 0 & 0 & 0 \\
\hline
\end{tabular}




\section{FIGURES}

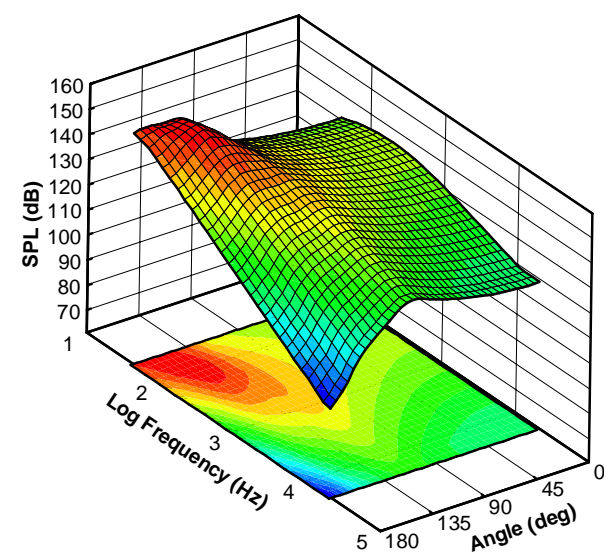

Figure 1. Far field sound pressure level predictions from a jet engine as function of frequency and directivity angle.

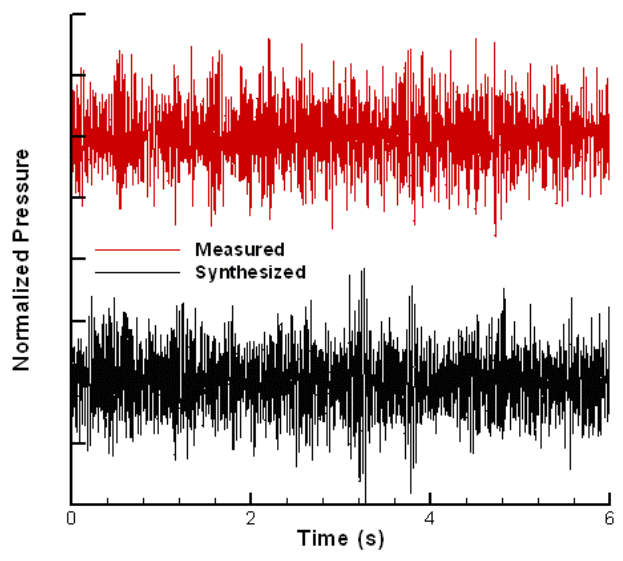

Figure 2. Measured jet noise time history and the noise synthesized from time-averaged measured data.

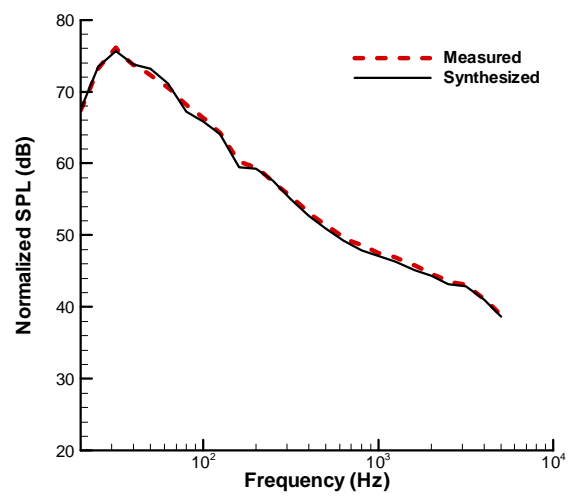

Figure 3. Time-averaged one-third octave band spectra of measured and synthesized jet noise data. Filters obtained from the measured spectrum were input to the synthesis.

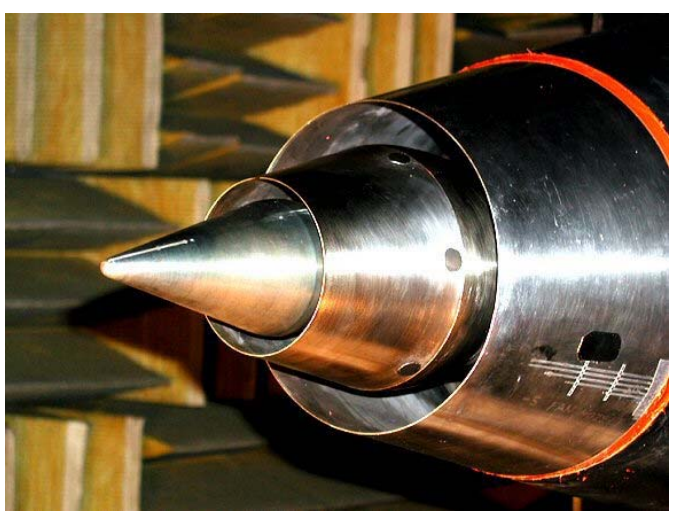

Figure 4. Engine exhaust nozzle model in the Low Speed Aeroacoustic Wind Tunnel (LSAWT) at the NASA Langley Jet Noise Laboratory.

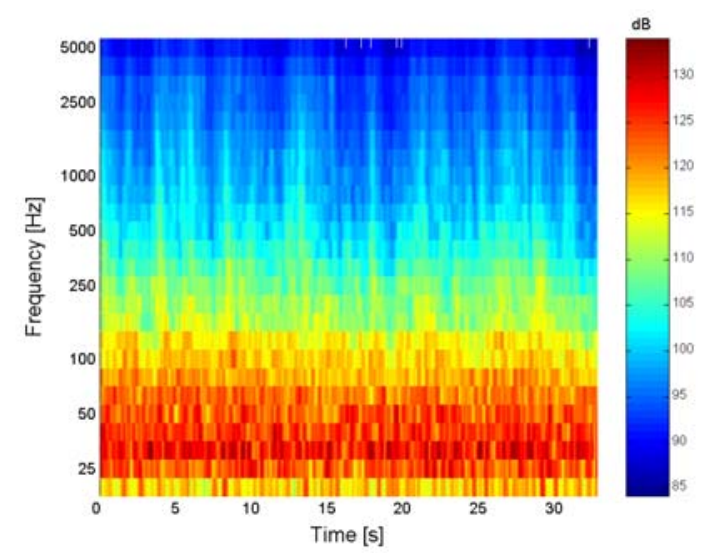

Figure 5. Spectrogram of measured broadband jet engine sound pressure levels at $95.5 \%$ overlap.

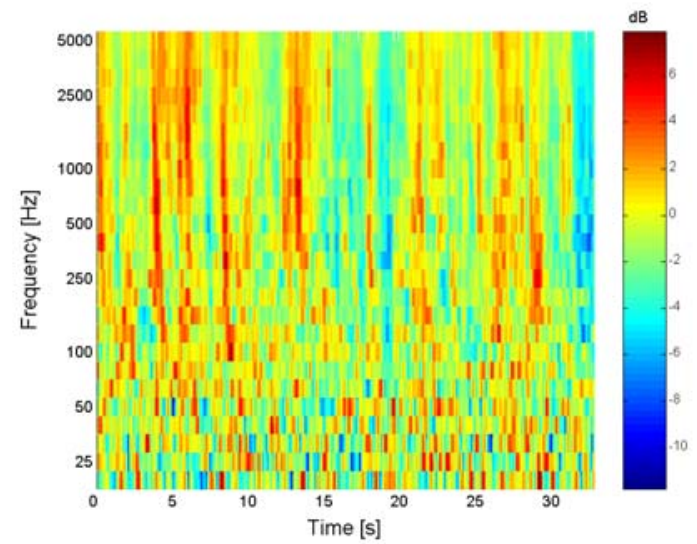

Figure 6. Variation of measured broadband jet engine sound pressure levels about the average value as function of frequency and time at $95.5 \%$ overlap. 


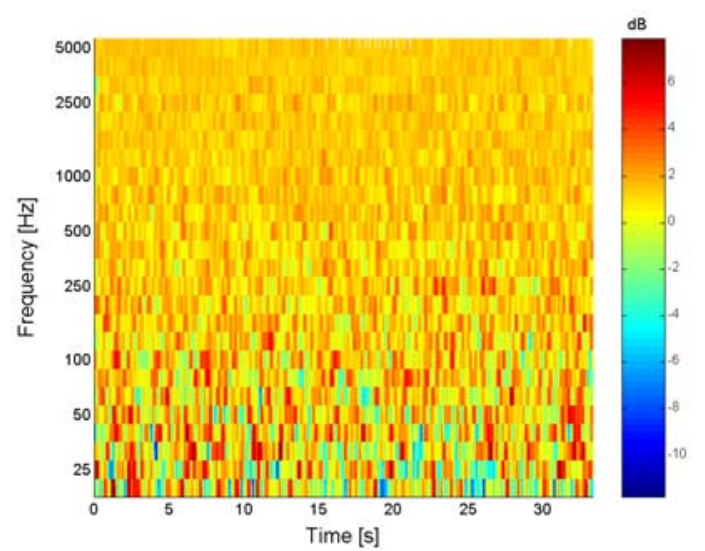

Figure 7. Variation of synthesized broadband jet engine noise without use of time variations about the average value as function of frequency and time at $95.5 \%$ overlap.

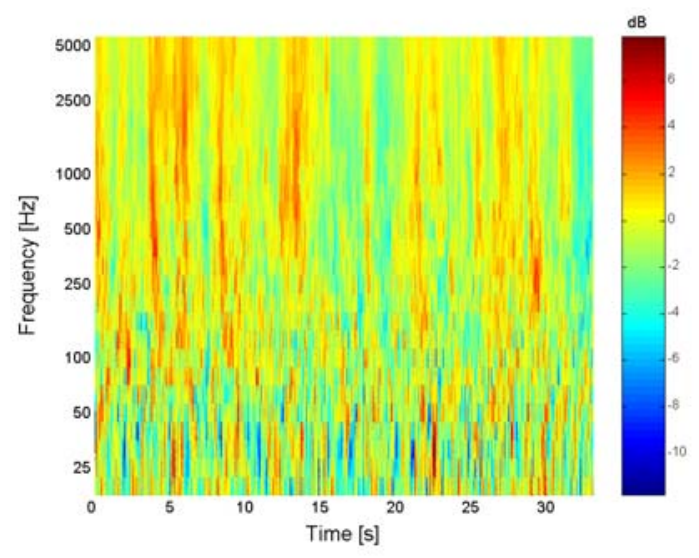

Figure 8. Variation of synthesized broadband jet engine noise with use of time variations about the average value as function of frequency and time at $95.5 \%$ overlap.

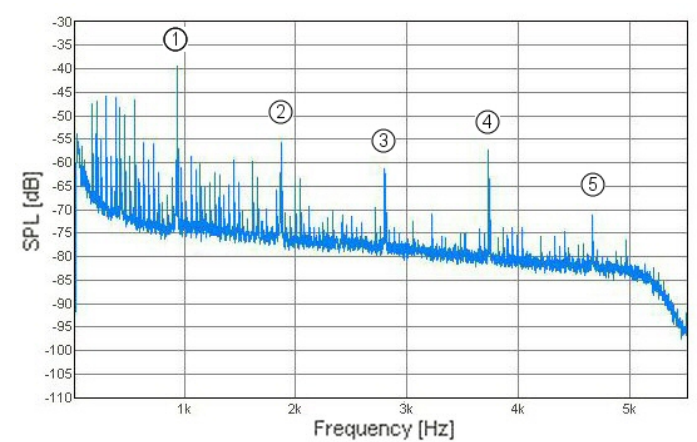

Figure 9. Fan wind tunnel model frequency spectrum scaled up in frequency to the full-size engine spectrum (take-off).

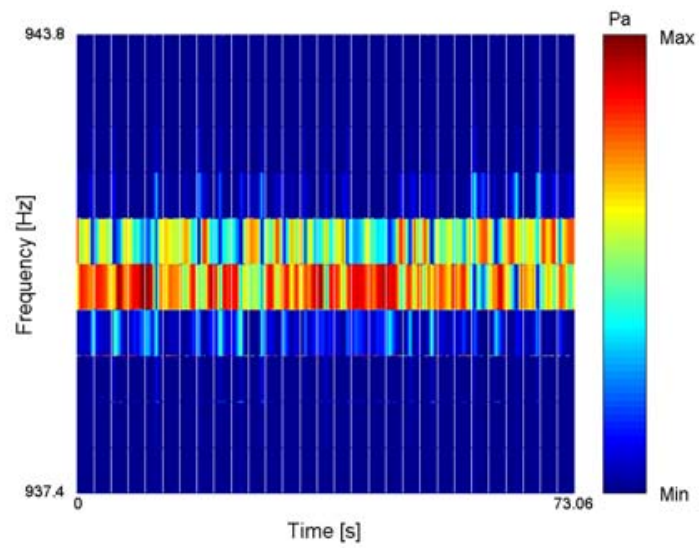

Figure 10. Spectrogram of ten frequency bins encompassing the $939.4 \mathrm{~Hz}$ BPF (take-off).

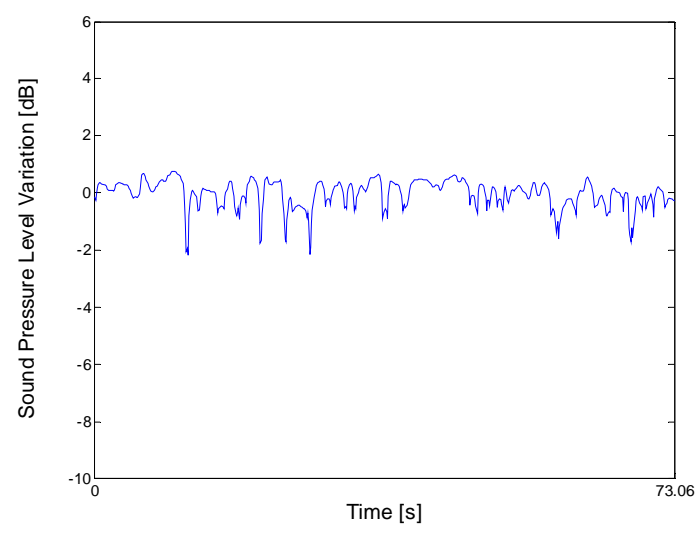

Figure 11. Sound pressure level variation about the time average of the $939.4 \mathrm{~Hz}$ BPF maximum sound pressure level (take off).

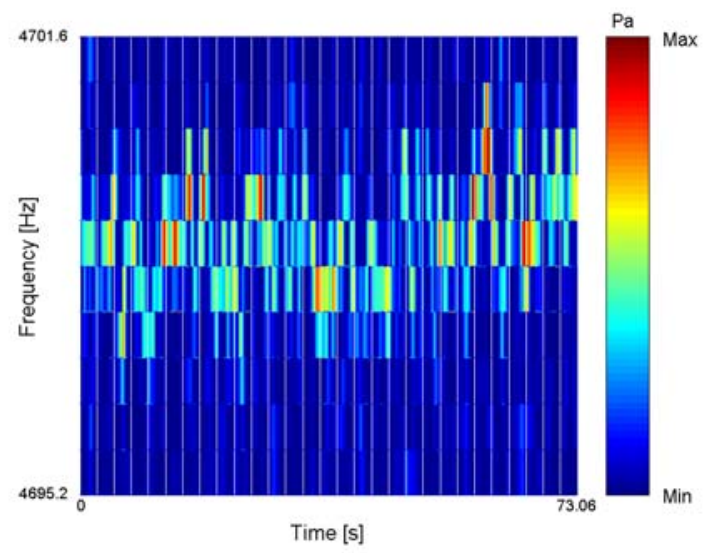

Figure 12. Spectrogram of ten frequency bins encompassing the $4697.0 \mathrm{~Hz}$ fifth harmonic of the BPF (take-off). 


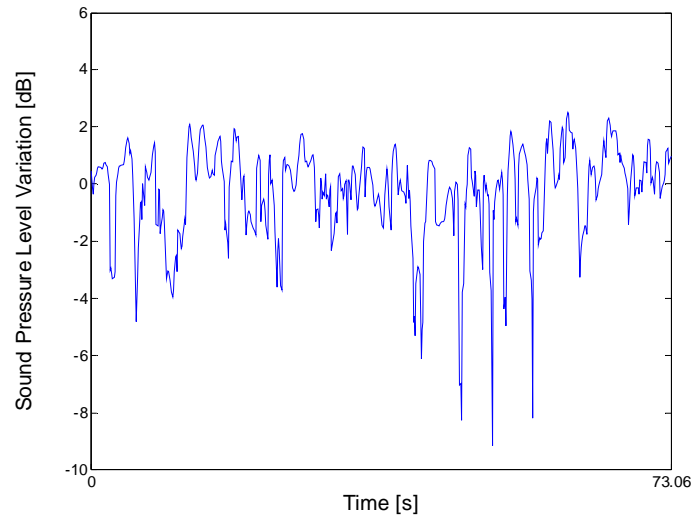

Figure 13. Sound pressure level variation about the time average of the $4697.0 \mathrm{~Hz}$ fifth harmonic of the BPF maximum sound pressure level (take off).

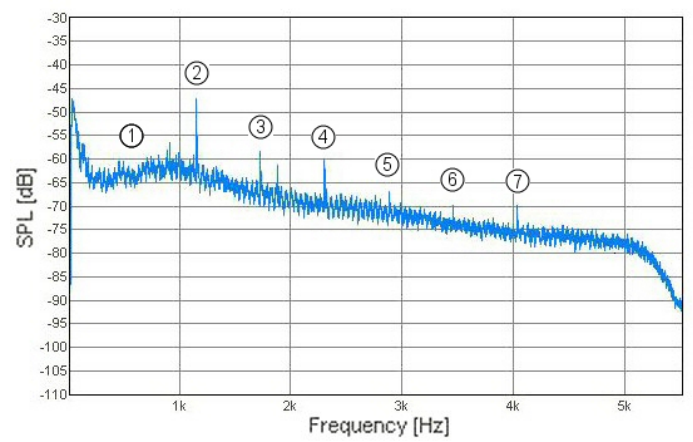

Figure 14. Fan wind tunnel model frequency spectrum scaled up to the full-size engine spectrum (approach).

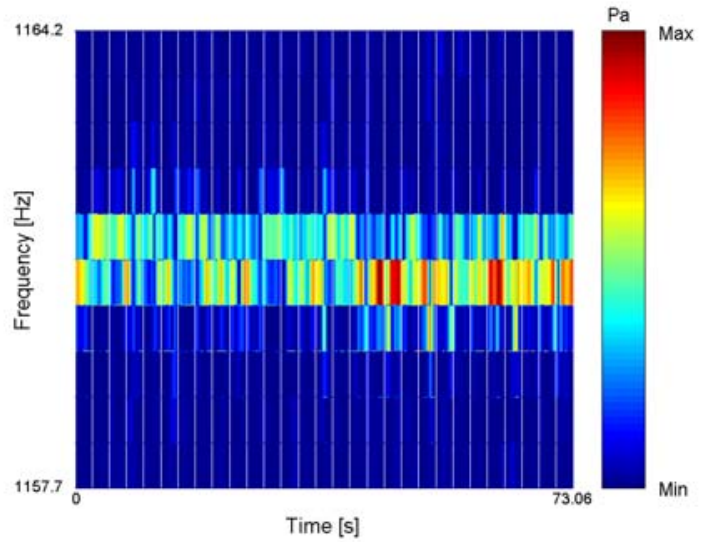

Figure 15. Spectrogram of ten frequency bins encompassing the $1159.4 \mathrm{~Hz}$ second harmonic of the BPF (approach).

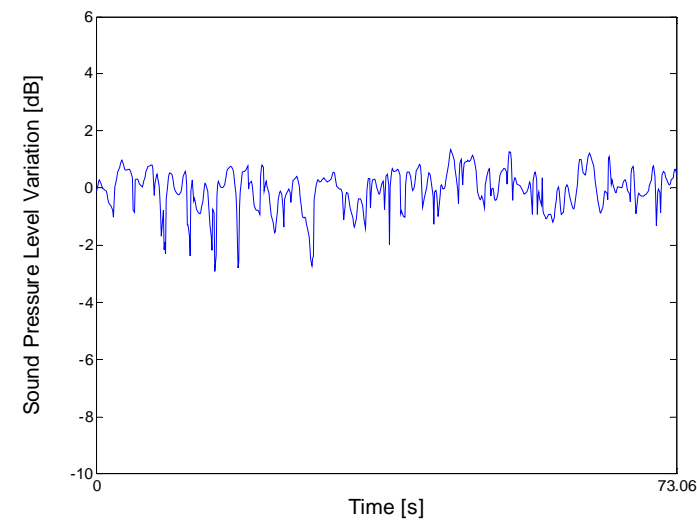

Figure 16. Sound pressure level variation about the time average of the $1159.4 \mathrm{~Hz}$ second harmonic of the BPF maximum sound pressure level (approach).

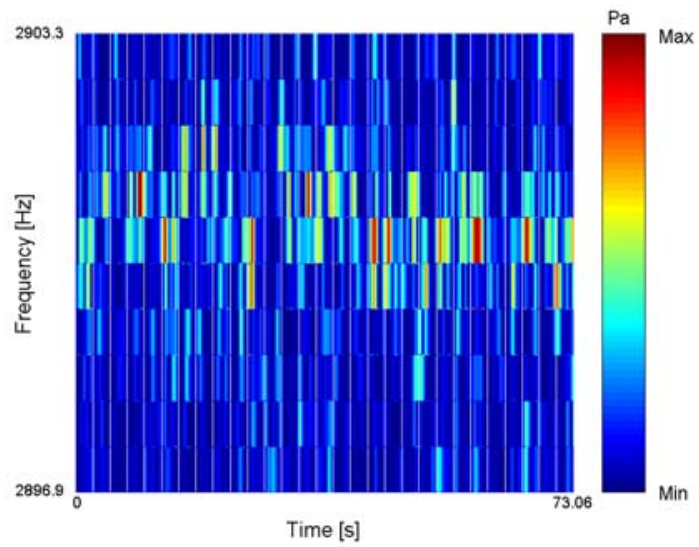

Figure 17. Spectrogram of ten frequency bins encompassing the $2898.5 \mathrm{~Hz}$ fifth harmonic of the BPF (approach).

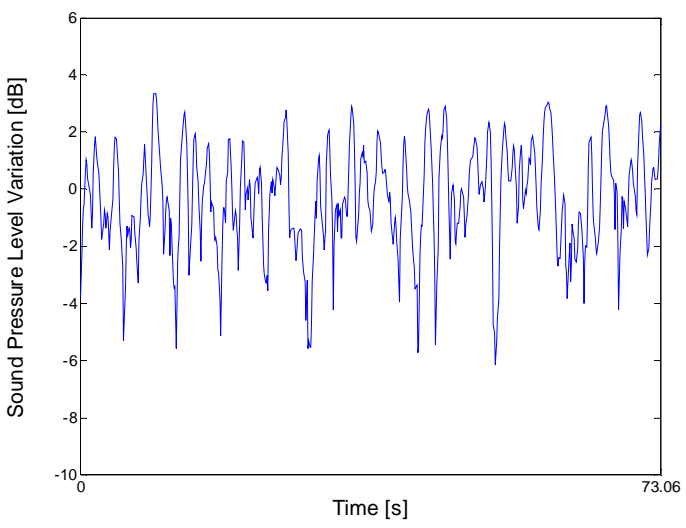

Figure 18. Sound pressure level variation about the time average of the $2898.5 \mathrm{~Hz}$ fifth harmonic of the BPF maximum sound pressure level (approach). 